\title{
Levantamento da Infestação de Plantas Daninhas Associada a uma Pastagem Cultivada de Baixa Produtividade no Nordeste Paraense ${ }^{1}$
}

\author{
Survey of Weeds Associated to Cultivated Low Yield Pastures in the Northern Region of Pará, \\ Brazil
}

MODESTO JÚNIOR, M.S. ${ }^{2}$ e MASCARENHAS, R.E.B. ${ }^{3}$

\begin{abstract}
RESUMO - A região do trópico úmido amazônico ocupa 350 milhões de hectares, constituindo a maior área de fronteira agrícola do planeta. A pecuária como exploração do uso da terra é a principal forma de ocupação e de desmatamento na região, apesar da baixa produtividade e das conseqüências ambientais. O declínio da produtividade da pastagem está associado, entre outras, ao manejo inadequado e à elevada infestação de plantas daninhas herbáceas e arbustivas, anuais ou perenes, geralmente denominadas "juquira” na região. Se essas plantas não forem controladas adequadamente, podem levar à degradação da pastagem, resultando na completa perda de produtividade e no posterior abandono da área. Com o objetivo de identificar as plantas daninhas mais importantes que ocorrem em área de pastagem de baixa produtividade no município de Terra Alta, PA ( $0^{\circ} 58^{\prime \prime} \mathrm{S}$ e $47^{\circ} 52^{\prime}$ W. Gr.), foi efetuado um levantamento florístico em 0,33 ha de área cultivada com capim-quicuio-da-amazônia (Brachiaria humidicola). Foram registrados 4.700 indivíduos, distribuídos em 17 famílias botânicas, representadas por 36 espécies vegetais. Destacaram-se as famílias Poaceae, Rubiaceae, Fabaceae, Asteraceae e Solanaceae, sendo encontrado em cada uma delas cinco, cinco, quatro, três e três espécies, respectivamente. As plantas daninhas consideradas de maior importância na comunidade vegetal foram: Borreria verticillata, Hyptis atrorubens, Rolandra argentea, Desmodium canum, Panicum pilosum, Davilla rugosa, Imperata brasiliensis, Paspalum maritimum, Vernonia scorpioides e Vismia guianensis.
\end{abstract}

Palavras-chave: levantamento botânico, amazônia, infestação, Brachiaria humidicola.

ABSTRACT - Pasture for raising cattle has been the major land use in the Amazon region of Brazil. This agricultural practice has caused environmental disturbances associated with deforestation and burning. After five or six years of intensive pasture, the land undergoes degradation due to poor management and high weed infestation. A survey was carried out to identify the main weeds in 0.33 ha pastures covered with Brachiaria humidicola in Terra Alta, located at the northern region of Pará - Brazil ( $0^{\circ} 58^{\prime \prime} \mathrm{S}$ e $47^{\circ}$ 52" W. Gr.). The 4,700 specimens were sorted out in 17 botanical families with 35 species belonging to Poaceae, Rubiaceae, Fabaceae, Asteraceae and Solanaceae, with five, five, four, three and three species being found, respectively. The most important weed species in the community were Borreria verticillata, Hyptis atrorubens, Rolandra argentea, Desmodium canum, Panicum pilosum, Davilla rugosa, Imperata brasiliensis, Paspalum maritimum, Vernonia scorpioides and Vismia guianensis.

Key words: $\quad$ botanical survey, Amazon region, infestation, Brachiaria humidicola.

1 Recebido para publicação em 3/1/2000 e na forma revisada em 19/1/2001.

2 Eng.-Agrônomo Embrapa Amazônia Oriental, Caixa Postal 48, 66095-100 Belém-PA; ${ }^{3}$ Eng.-Agrônomo, M.S. Embrapa Amazônia Oriental. 


\section{INTRODUÇÃO}

A região do trópico úmido amazônico ocupa 350 milhões de hectares, constituindo a maior área de fronteira agrícola do planeta (Veiga \& Serrão, 1987).

O Estado do Pará possuía, em 1995, cerca de 1,6 milhão de ha de pastagens nativas e 5,8 milhões de ha de pastagens plantadas e abrigava um rebanho de 6,08 milhões de cabeças de bovinos e 312 mil cabeças de bubalinos (Censo Agropecuário, 1995-1996). Quando comparado com os dados obtidos em 1985 (Censo Agropecuário, 1985), observa-se que ocorreu declínio da ordem de 715 mil ha de pastagens nativas e incremento de 1,6 milhão de ha de pastagens plantadas. Isto deve-se provavelmente à formação de pastagens plantadas em áreas que antes eram pastagens naturais e também à elevada pecuarização que ocorreu no período (Censo Agropecuário, 1995-1996). Desse modo, a pecuária como atividade de exploração do uso da terra é a principal forma de ocupação e uma das causas do desmatamento na região, apesar da baixa produtividade e das conseqüências ambientais.

O declínio da produtividade da pastagem está associado ao superpastejo, à baixa fertilidade do solo, a queimadas indiscriminadas, ao manejo inadequado e à elevada infestação de plantas daninhas herbáceas, arbustivas, anuais ou perenes, genericamente denominadas "juquira" na região. Segundo Dias Filho (1998), se as plantas daninhas não forem controladas adequadamente, nem implementadas medidas para o restabelecimento da produtividade das forrageiras, pode ocorrer alta infestação das plantas daninhas, levando à degradação da pastagem, resultando na completa perda de produtividade e no posterior abandono da área.

Não existem estudos quantitativos dos gastos para o controle da "juquira" em pastagens, entretanto Hecht (1979) estimou que 10 a $20 \%$ dos custos de produção de uma fazenda em Paragominas, PA, foram gastos nesta atividade.

O Nordeste Paraense apresenta destacada importância relativa em termos populacionais, de infra-estrutura e de participação econômica, tanto na área de influência da região metropolitana da grande Belém, como de todas as cidades situadas próximas ao eixo rodoviário das estradas federais de integração nacional BR 316 e BR 010, que ligam a região Norte com todo o País. O município de Terra Alta está inserido no Nordeste Paraense, onde a criação de gado é feita em regime semi-intensivo nas áreas de pastagens cultivadas (Homma et al., 1977; Azevedo et al., 1994), que são formadas geralmente por meio do sistema tradicional de preparo de área através de roçada (broca), derrubada e queima da biomassa, seguida de plantio de gramíneas forrageiras.

O levantamento é importante para que se obtenha o conhecimento sobre as populações de plantas daninhas através dos parâmetros de freqüência e abundância e da biologia das espécies encontradas, que, analisados em conjunto, indicarão as medidas de controle mais adequadas a utilizar.

Devido à localização privilegiada do município e visando o manejo e controle de plantas daninhas para a recuperação e o aumento da produtividade de pastagens cultivadas em áreas de baixa fertilidade, foi efetuado um levantamento florístico para determinar as plantas daninhas mais importantes que ocorrem em uma pastagem de Terra Alta-PA.

\section{MATERIAL E MÉTODOS}

O trabalho foi desenvolvido na Fazenda Belém, em outubro de 1997, no município de Terra Alta-PA, distante em torno de $100 \mathrm{~km}$ da cidade de Belém, maior centro consumidor da região Norte ( $0^{\circ} 58^{\prime}$ ' S e $47^{\circ} 52^{\prime}$ W. Gr.), à margem direita da rodovia PA 136, no sentido Castanhal - Curuçá.

O solo foi classificado como Latossolo Amarelo com textura leve e, de acordo com valores médios de 1974 a 1987 das principais variáveis climáticas, da cidade de Castanhal, a $37 \mathrm{~km}$ da área do experimento, a temperatura máxima atingiu $31,7{ }^{\circ} \mathrm{C}$ e a mínima $22,1{ }^{\circ} \mathrm{C}$, a umidade relativa média do ar foi de $85 \%$ e a precipitação pluviométrica mensal foi superior a $60 \mathrm{~mm}$, com volume anual de 2.586,8 mm (Boletim..., 1974 - 1987).

Selecionou-se uma área de pastagem com mais de dez anos de idade, cultivada com capimquicuio-da-amazônia (Brachiaria humidicola, e, 
visualmente, $80 \%$ da área estava dominada por plantas daninhas.

O levantamento florístico de plantas daninhas foi efetuado em 0,33 ha de área $(30 \mathrm{~m} \mathrm{x}$ $100 \mathrm{~m}$ ), dividida em oito parcelas de $15 \mathrm{~m} \mathrm{x}$ $25 \mathrm{~m}$. De cada parcela foram coletadas sete amostras ao acaso, utilizando-se um quadrado de madeira com um metro de lado. Toda a vegetação daninha contida no interior do quadrado, local da amostra, foi cortada ao nível do solo e separada por espécie, sendo contados todos os seus respectivos indivíduos. Em seguida, o material foi prensado, secado em estufa elétrica à temperatura de $40{ }^{\circ} \mathrm{C}$ e enviado ao Herbário IAN*, no qual foi identificado por meio de morfologia comparada e incorporado ao seu acervo, através de exsicatas.

A freqüência absoluta foi calculada por meio da relação percentual entre o número de amostras em que a espécie foi encontrada e o total de amostras efetuadas na área, e a freqüência relativa, através da razão entre a freqüência absoluta de cada espécie e a somatória das freqüências absolutas de todas as espécies. No cálculo da densidade foi empregada a relação entre o total de indivíduos de cada espécie e o total de amostras efetuadas.

As espécies foram relacionadas segundo suas famílias, em ordem alfabética, nas quais estão listados nomes científicos revisados de acordo com o Index (1993), nomes vulgares, ciclo de vida, hábito de crescimento, consistência do caule, meios de reprodução, toxidez e injúrias, cujas informações foram obtidas por meio de observações de campo e de consultas bibliográficas e ao Herbário do IAN.

\section{RESULTADOS E DISCUSSÃO}

O levantamento totalizou 4.700 indivíduos, distribuídos em 17 famílias, representadas por 36 espécies, sendo 7 monocotiledôneas (20\%) e 29 dicotiledôneas (80\%). Estes resultados estão de acordo com os obtidos por Dantas \& Rodrigues (1980), em pastagem cultivada, em Paragominas-PA, Santana do Araguaia-PA e

\footnotetext{
* Atualmente o laboratório de Botânica da Embrapa Amazônia Oriental, criado em 1945, foi indexado internacionalmente com a sigla IAN (Instituto Agronômico do Norte).
}

Itacoatiara-AM e por Vinha et al. (1983) em Santa Cruz Cabrália-BA.

Nas famílias Poaceae e Rubiaceae foi registrado o maior número de espécies (5), seguidas de Leguminosae (4), Asteraceae (3) e Solanaceae (3). Essas famílias também foram citadas por Camarão et al. (1990) em pastagens cultivadas, em Paragominas (PA), como as que concentraram maior número de espécies. Os gêneros que mais se destacaram foram Borreria, Desmodium e Solanum, cada um representado por três espécies. As espécies Borreria verticillata, Hyptis atrorubens, Rolandra argentea, Desmodium canum e Panicum pilosum apresentaram os maiores números de indivíduos $(949,925,894,720$ e 300 , respectivamente, conforme pode ser visto na Tabela 1.

Verifica-se, na Figura 1, que a maioria das espécies apresenta baixa densidade de indivíduos. Do total de 36 espécies, 29 (correspondente a 80\%) apresentaram entre 1 e 100 indivíduos e o restante ficou distribuído em classes maiores. Na maior classe encontrada (901 - 1.000) foram registradas apenas duas espécies, que foram Borreria verticillata e Hyptis atrorubens. Resultados semelhantes foram encontrados por Mascarenhas et al. (1996 e 1997) em levantamentos florísticos de plantas daninhas efetuados em área de várzea do rio Guamá, estuário amazônico, que relataram a ocorrência de poucas espécies dominantes, representadas por muitos indivíduos, e muitas espécies com poucos indivíduos.

Na Figura 2 é apresentada a curva cumulativa do aparecimento de novas espécies, segundo o número de amostras, em ascensão, indicando que uma área maior deveria ter sido estudada, a fim de se obter uma amostragem mais representativa do seu conteúdo em espécies, hipótese que está de acordo com Pires \& Koury (1959). Segundo estes autores, terse-ia sempre que trabalhar em uma área muito maior para encontrar mais espécies ali representadas, raras ou não. Para Blanco (1976), a área de amostragem, em levantamento de plantas daninhas, estaria em torno de 5\% da área total estudada.

Na Tabela 1, observa-se que $86 \%$ das espécies possuem densidades muito baixas e que as mais densas também foram as mais freqüentes. Também ficou evidenciado que a maioria das espécies tem freqüência muito 
baixa, confirmando o que já havia sido observado por Dantas \& Rodrigues (1980) e Mascarenhas et al. (1996 e 1997).

Em ordem decrescente, destacaram-se como as mais densas e freqüentes as espécies Borreria verticillata (16,95 plantas $\mathrm{m}^{-2}$ e $\left.12,56 \%\right)$, Hyptis atrorubens (16,52 plantas $\mathrm{m}^{-2}$ e 8,29\%), Rolandra argentea (15,96 plantas $\mathrm{m}^{-2}$ e 12,56\%), Desmodium canum $\left(12,86\right.$ plantas $\mathrm{m}^{-2}$ e $\left.12,32 \%\right)$ e Panicum pilosum (5,36 plantas $\mathrm{m}^{-2}$ e 5,45\%). Segundo esquema de Bleasdale (1960), modificado por Blanco (1972), o grau de competição das plantas daninhas com os cultivos agrícolas depende de fatores ligados à espécie cultivada (cultivar, espaçamento, densidade de semeadura e tratos culturais) e à comunidade infestante (composição específica, abundância e freqüência), da época e da extensão do período de convivência e do ambiente em que se desenvolve a interação. Como o percentual de cobertura de solo pela forrageira Brachiaria humidicola foi obtido visualmente, na ordem de $20 \%$, será necessária a recuperação da pastagem com a intensificação do uso de tecnologias adequadas de manejo, associadas ao controle integrado de plantas daninhas, para evitar a completa perda da produtividade da pastagem devido à infestação total das plantas daninhas.

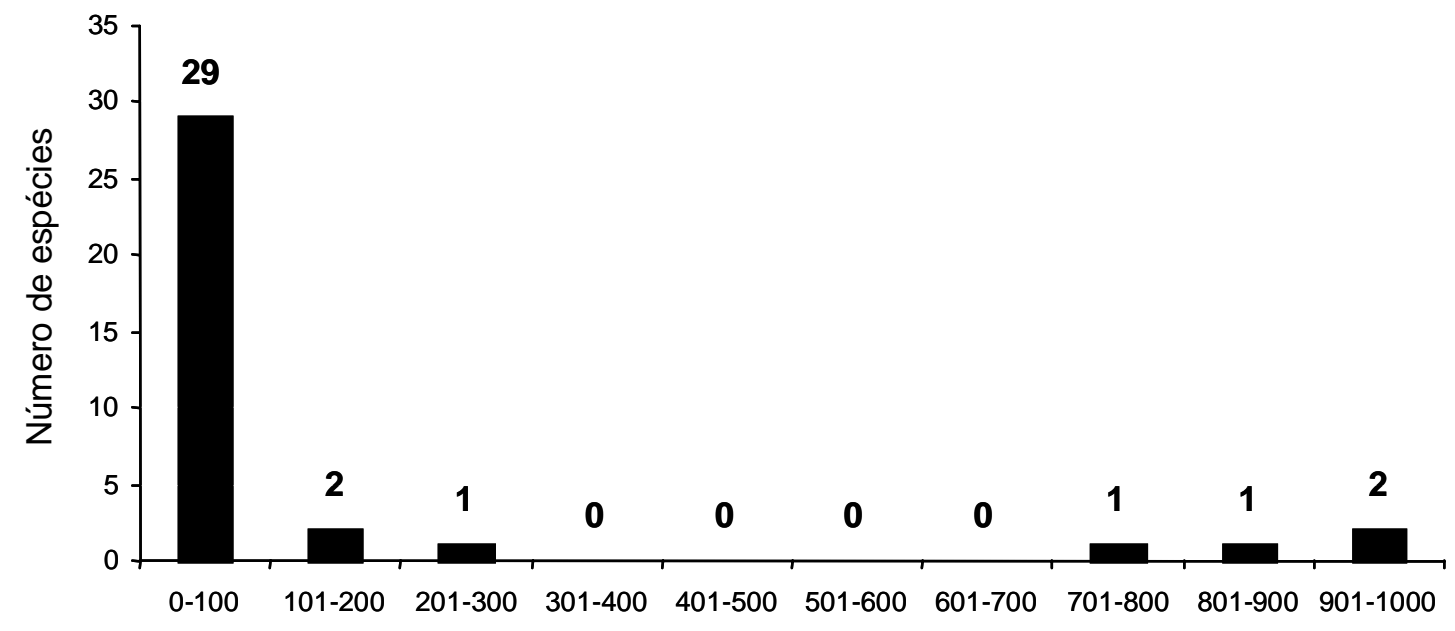

- Número de indivíduos

Figura 1 - Número de espécies por classes de número de indivíduos.

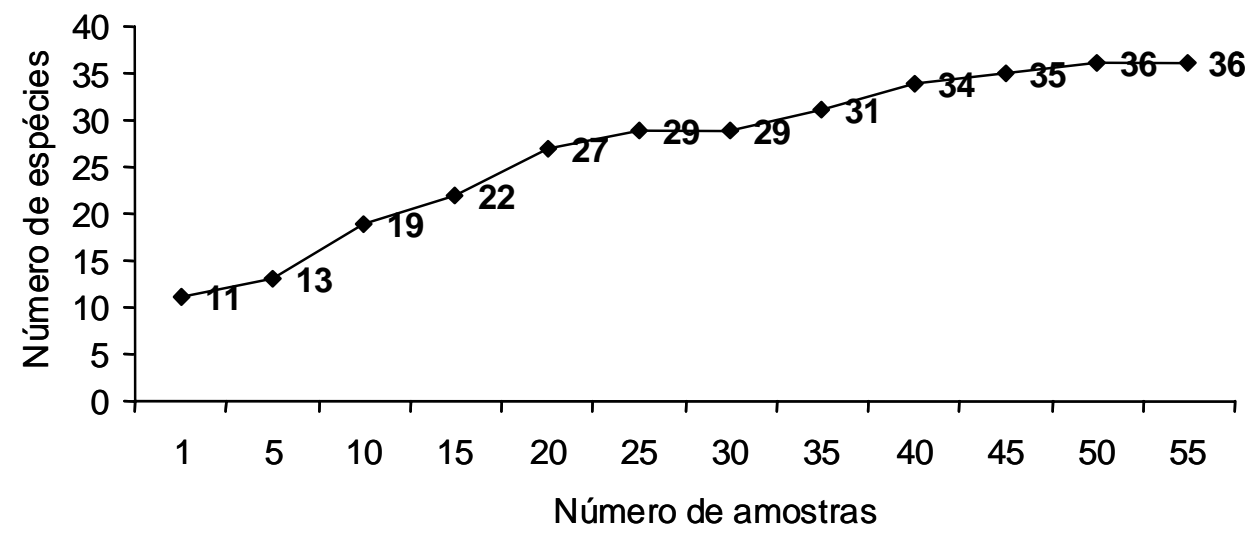

Figura 2 - Curva cumulativa do aparecimento de novas espécies. 
Tabela 1 - Nome científico, total de indivíduos amostrados, número de amostras em que a espécie foi encontrada, densidade, freqüência absoluta e relativa das espécies de plantas daninhas levantadas em uma pastagem cultivada de baixa produtividade no Nordeste Paraense, Terra Alta, 1997

\begin{tabular}{|c|c|c|c|c|c|}
\hline \multirow{2}{*}{ Nome científico } & \multirow{2}{*}{$\begin{array}{l}\mathrm{N}^{\mathrm{o}} \text { total de } \\
\text { indivíduos } \\
\text { amostrados }\end{array}$} & \multirow{2}{*}{$\begin{array}{c}\text { № de amostras } \\
\text { em que a } \\
\text { espécie foi } \\
\text { encontrada }\end{array}$} & \multirow{2}{*}{$\begin{array}{c}\text { Densidade } \\
\left(\text { plantas } / \mathrm{m}^{2}\right)\end{array}$} & \multicolumn{2}{|c|}{$\begin{array}{c}\text { Freqüência } \\
(\%)\end{array}$} \\
\hline & & & & Absoluta & Relativa \\
\hline Banara guianensis Aubl. & 1 & 1 & 0,02 & 1,78 & 0,24 \\
\hline Borreria latifolia Schum. & 98 & 18 & 1,75 & 32,14 & 4,26 \\
\hline Borreria suaveolens G.F.W. Mey. & 1 & 1 & 0,02 & 1,78 & 0,24 \\
\hline Borreria verticilata (L.) G.F.W. Mey & 949 & 53 & 16,95 & 94,64 & 12,56 \\
\hline Casearia arborea Urb. & 1 & 1 & 0,02 & 1,78 & 0,24 \\
\hline Coutoubea spicata H.B. \& K. & 1 & 1 & 0,02 & 1,78 & 0,24 \\
\hline Davilla rugosa Poir. & 10 & 5 & 0,18 & 8,93 & 1,18 \\
\hline Desmodium axilare DC. & 21 & 4 & 0,37 & 7,14 & 0,95 \\
\hline Desmodium barbatum Benth. \& Oerst. & 155 & 35 & 2,77 & 62,50 & 8,29 \\
\hline Desmodium canum Vahl. & 720 & 52 & 12,86 & 92,86 & 12,32 \\
\hline Dichromena ciliata Vahl. & 5 & 3 & 0,09 & 5,36 & 0,71 \\
\hline Elephantopolis mollis H. B. \& K. & 28 & 11 & 0,50 & 19,64 & 2,61 \\
\hline Hemidiodia ocimifolia Schum. & 4 & 2 & 0,07 & 3,57 & 0,47 \\
\hline Homolepis aturensis Chase & 18 & 4 & 0,32 & 7,14 & 0,95 \\
\hline Hyptis atrorubens Poit. & 925 & 35 & 16,52 & 62,50 & 8,29 \\
\hline Imperata brasiliensis Trin. & 41 & 5 & 0,73 & 8,93 & 1,18 \\
\hline Lecythis lurida (Miers) S.A. Mori. & 1 & 1 & 0,02 & 1,78 & 0,24 \\
\hline Memora allamandiflora Bureau ex. K. Shum. & 2 & 1 & 0,03 & 1,78 & 0,24 \\
\hline Memora flavida Bureau ex. K. Shum. & 15 & 10 & 0,27 & 17,86 & 2,37 \\
\hline Panicum pilosum $\mathrm{SW}$. & 300 & 23 & 5,36 & 41,07 & 5,45 \\
\hline Paspalum conjugatum Berg. & 95 & 7 & 1,70 & 12,50 & 1,66 \\
\hline Paspalum maritimum Trin. & 57 & 3 & 1,02 & 5,36 & 0,71 \\
\hline Pterolepis tricotoma Cogn. & 48 & 11 & 0,86 & 19,64 & 2,61 \\
\hline Rolandra argentea Rottb. & 894 & 53 & 15,96 & 94,64 & 12,56 \\
\hline Sabicea villosa Roen. \& Shut. & 158 & 38 & 2,82 & 67,86 & 9,00 \\
\hline Sckrankia leptocarpa DC. & 1 & 1 & 0,02 & 1,78 & 0,24 \\
\hline Scleria bracteata Cav. & 88 & 13 & 1,57 & 23,21 & 3,08 \\
\hline Sida rhombifolia Linn. & 1 & 1 & 0,02 & 1,78 & 0,24 \\
\hline Sida urens Linn. var. urens & 3 & 3 & 0,05 & 5,36 & 0,71 \\
\hline Solanum caavurana Lam. & 1 & 1 & 0,02 & 1,78 & 0,24 \\
\hline Solanum crinitum Lam. & 1 & 1 & 0,02 & 1,78 & 0,24 \\
\hline Solanum stramonifolium Jacq. & 4 & 2 & 0,07 & 3,57 & 0,47 \\
\hline Stachytapheta cayenensis Schau & 7 & 5 & 0,12 & 8,93 & 1,18 \\
\hline Tabernaemontana angulata Mart. ex. Muell. Arg. & 1 & 1 & 0,02 & 1,78 & 0,24 \\
\hline Vernonia scorpioides Pers. & 22 & 4 & 0,39 & 7,14 & 0,95 \\
\hline Vismia guianensis (Aublet) Choisy & 23 & 12 & 0,41 & 21,43 & 2,84 \\
\hline TOTAL & 4.700 & 56 & - & 753,50 & 100,00 \\
\hline
\end{tabular}


A espécie Borreria verticillata, considerada a mais importante, também foi citada como uma das mais infestantes na região de ManausAM (Teixeira et al., 1973), na Zona Bragantina, no Baixo Amazonas e em Paragominas-PA (Gonçalves et al., 1974) e na Amazônia Ocidental (Souza et al., 1997).

As espécies Davilla rugosa, Imperata brasiliensis, Paspalum maritimum, Vernonia scorpioides e Vismia guianensis, apesar de não estarem entre as mais densas e freqüentes, também são consideradas importantes em razão de suas características de reprodução, adaptação, agressividade e competição com a forrageira cultivada.

Na Tabela 2 estão relacionadas as características botânicas das plantas daninhas, consideradas, de acordo com Mascarenhas et al. (1999), importantes para auxiliar na escolha dos métodos de controle. As estimativas mostram que 39\% das espécies apresentam ciclo de vida perene, $55 \%$ possuem consistência do caule lenhoso e $25 \%$ mostram predominância do hábito de crescimento subarbustivo. Todas as espécies se reproduzem por sementes, e 30\% do total também se propaga vegetativamente. Esses dados indicam que as espécies perenes apresentam quantidade significativa (39\%) e, devido às suas características de propagação vegetativa, são consideradas de difícil controle. Por outro lado, também se deve ter cuidado com as espécies anuais, que, por questão de sobrevivência, produzem grandes quantidades de sementes com dormência, acessórios especiais de disseminação e desenvolvem-se com maior facilidade que a planta cultivada (Deuber, 1992).

A alta capacidade reprodutiva, a proliferação e as características especiais de disseminação, dormência e viabilidade constituem os problemas mais complexos no controle de plantas daninhas, tornando o controle da maioria das espécies bastante difícil. Em pastagens, dificilmente um método de controle aplicado isoladamente é totalmente eficiente, pois os resultados mais efetivos e duradouros são obtidos quando se faz a integração dos diferentes métodos, estabelecendo-se um plano racional de manejo (Dias Filho, 1990; Deuber 1992). As medidas preventivas, que consistem no uso de práticas que visam reduzir a introdução, o estabelecimento e a disseminação de determinadas espécies em áreas onde ainda não estejam presentes, deverão, portanto, ser adotadas, em qualquer situação, como princípio básico (Deuber, 1992).

Com relação à toxidez, apenas três espécies são suspeitas de serem tóxicas e cinco causam injúrias na forma de feridas ao homem e aos animais. Segundo Albuquerque (1980), a invasora Davilla rugosa parece ser um purgativo drástico, enquanto Panicum pilosum e Homolepis aturensis constam ser cianogenéticas. De acordo com Diaz et al. (1978), a última espécie apresentou $180 \mathrm{mg} \mathrm{HCN} \mathrm{kg}^{-1}$ em planta fresca. Em ovelhas, a dose mínima letal de HCN livre é de $2,4 \mathrm{mg} \mathrm{kg}^{-1}$ de peso, podendo elas tolerarem de 15 a $20 \mathrm{mg} \mathrm{HCN} \mathrm{kg}^{-1}$ por dia, quando a ingestão for lenta (Butler et al., 1973, citados por Diaz et al., 1978). Em razão da dificuldade de determinar todas as plantas daninhas tóxicas em pastagens, aconselha-se ao pecuarista controlar a infestação de qualquer planta suspeita.

Apesar de as espécies levantadas (Tabelas 1 e 2) serem consideradas plantas daninhas propriamente ditas, existem algumas que, não sendo tóxicas, são potencialmente aproveitáveis como forrageiras, sob o ponto de vista nutricional, conforme relataram Serrão \& Falesi (1977). Na pastagem estudada, foram citadas como exemplo as espécies Rolandra argentea, Borreria latifolia, Desmodium canum e Stachytarpheta cayennensis, que foram bastante consumidas pelo gado, conforme Camarão et al. (1990). Segundo Serrão \& Falesi (1977), talvez o gênero Desmodium seja o mais importante das leguminosas encontradas nas comunidades das plantas daninhas de pastagens cultivadas, que são pastejadas pelo gado.

O levantamento florístico quantitativo realizado em conjunto com as observações visuais e as características botânicas, aliadas à alta adaptação e agressividade das espécies, permitem concluir que as plantas daninhas Borreria verticillata, Hyptis atrorubens, Rolandra argentea, Desmodium canum, Panicum pilosum, Davilla rugosa, Imperata brasiliensis, Paspalum maritimum, Vernonia scorpioides e Vismia guianensis foram consideradas as mais importantes. 
Tabela 2 - Família, nome científico, nome comum, ciclo de vida, hábito de crescimento, consistência do caule, reprodução, plantas tóxicas e que causam injúrias ao homem e aos animais, em pastagens cultivadas de baixa produtividade em Terra Alta-PA, Fazenda Belém, a 37 km de Castanhal, outubro de 1997

\begin{tabular}{|c|c|c|c|c|c|c|}
\hline $\begin{array}{l}\text { FAMÍLIA / NOME } \\
\text { CIENTÍFICO }\end{array}$ & $\begin{array}{c}\text { NOME } \\
\text { VULGAR }\end{array}$ & $\begin{array}{l}\text { CICLO DE } \\
\text { VIDA }\end{array}$ & $\begin{array}{c}\text { HÁBITO DE } \\
\text { CRESCIMENTO / } \\
\text { CONSISTÊNCIA DO } \\
\text { CAULE }\end{array}$ & REPRODUÇÃO & $\begin{array}{l}\text { TÓXICAS / } \\
\text { INJÚRIAS }\end{array}$ & REFERÊNCIAS \\
\hline $\begin{array}{l}\text { APOCYNACEAE } \\
\text { Tabernaemontana angulata } \\
\text { Mart. ex Muell. Arg. }\end{array}$ & $\begin{array}{l}\text { Pocoró, jasmim- } \\
\text { da-mata, jasmim- } \\
\text { de-cachorro (2) }\end{array}$ & - & $\begin{array}{l}\text { Arbustivo (1) / Lenhoso } \\
\text { (1) }\end{array}$ & Sementes (1) & - & $\begin{array}{l}\text { 1- Obs. de campo } \\
\text { 2- Herbário IAN }\end{array}$ \\
\hline $\begin{array}{l}\text { ASTERACEAE } \\
\text { Eleplantopus mollis } \text { H.B. \& K. }\end{array}$ & $\begin{array}{l}\text { Língua-de-vaca, } \\
\text { fumo-bravo, fumo- } \\
\text { da-mata, pé-de- } \\
\text { elefante, erva-de- } \\
\text { viado, erva-grossa } \\
\text { (4) }\end{array}$ & $\begin{array}{l}\text { Perene }(3,4 \text {, } \\
\text { 5) }\end{array}$ & $\begin{array}{l}\text { Ereto }(4,5) \text { / Herbáceo } \\
(\mathbf{1}, \mathbf{3}) \text { ou sublenhoso }(\mathbf{3})\end{array}$ & $\begin{array}{l}\text { Sementes }(1, \\
3,4,5)\end{array}$ & - & $\begin{array}{l}\text { 1- Obs. de campo } \\
\text { 2- Herbário IAN } \\
\text { 3- Corrêa (1952) } \\
\text { 4- Kissmann \& } \\
\text { Groth (1992) } \\
\text { 5- Lorenzi (1976) }\end{array}$ \\
\hline Rolandra argentea Rottb. & Acarycoá (2) & - & Ereto (1) / Herbáceo (1) & Sementes (1) & - & $\begin{array}{l}\text { 1- Obs. de campo } \\
\text { 2- Herbário IAN }\end{array}$ \\
\hline Vernonia scorpioides Pers. & $\begin{array}{l}\text { Enxuga (2), erva- } \\
\text { são-simão (3) }\end{array}$ & Perene (2), (3) & $\begin{array}{l}\text { Subarbustivo / } \\
\text { Lenhoso }(\mathbf{1}, \mathbf{2})\end{array}$ & $\begin{array}{l}\text { Sementes (1, } \\
\text { 2), estacas (3) }\end{array}$ & - & $\begin{array}{l}\text { 1- Obs. de campo } \\
\text { 2- Corrêa (1931) } \\
\text { 3- Lorenzi (1976) }\end{array}$ \\
\hline $\begin{array}{l}\text { BIGNONIACEAE } \\
\text { Memora allamandiflora } \\
\text { Bureau ex. K. Schum. }\end{array}$ & - & - & Liana (2) / Lenhosa $(\mathbf{1}, \mathbf{2})$ & $\begin{array}{l}\text { Sementes }(1, \\
\text { 2) }\end{array}$ & - & $\begin{array}{l}\text { 1- Obs. de campo } \\
\text { 2- Herbário IAN }\end{array}$ \\
\hline $\begin{array}{l}\text { Memora flavida Bureau \& K. } \\
\text { Schum. }\end{array}$ & Graxama (3) & - & $\begin{array}{l}\text { Liana }(1,2) \text { / Lenhosa }(1, \\
\text { 2) }\end{array}$ & Sementes (1) & - & $\begin{array}{l}\text { 1- Obs. de campo } \\
\text { 2- Herbário IAN } \\
\text { 3- Camarão et al. } \\
\text { (1990) }\end{array}$ \\
\hline $\begin{array}{l}\text { CYPERACEAE } \\
\text { Scleria bracteata } \text { Cav. }\end{array}$ & $\begin{array}{l}\text { Tiririca (2), } \\
\text { rasteira, tiririca-de- } \\
\text { navalha (3) }\end{array}$ & Perene (2) & $\begin{array}{l}\text { Decumbente }(1,2) / \\
\text { Herbáceo }(\mathbf{1}, \mathbf{2}, \mathbf{3})\end{array}$ & $\begin{array}{l}\text { Sementes, } \\
\text { rizomas (1) }\end{array}$ & $\begin{array}{l}\text { Folhas } \\
\text { cortantes (1) }\end{array}$ & $\begin{array}{l}\text { 1- Obs. de campo } \\
\text { 2- Herbário IAN } \\
\text { 3- Corrêa } 1974 \\
\end{array}$ \\
\hline Dichromena ciliata Vahl. & $\begin{array}{l}\text { Capim-estrela, } \\
\text { estrelinha }(2,3)\end{array}$ & Perene $(1,2,3)$ & $\begin{array}{l}\text { Cespitosa ereta } \\
(1,2,3) / \text { Herbáceo }(\mathbf{1}, \mathbf{2}, \mathbf{3})\end{array}$ & $\begin{array}{l}\text { Sementes } \\
(1,2,3)\end{array}$ & & $\begin{array}{l}\text { 1-Cárdenas et al. } \\
\text { (1972) } \\
\text { 2-Morales et al. } \\
\text { (1974) } \\
\text { 3-Obs. de campo. }\end{array}$ \\
\hline $\begin{array}{l}\text { DILLENIACEAE } \\
\text { Davilla rugosa } \text { Poir. }\end{array}$ & $\begin{array}{l}\text { Cipó-de-fogo (2), } \\
\text { cipó-caboclo, capa- } \\
\text { homem (3) }\end{array}$ & Perene (1) & $\begin{array}{l}\text { Liana }(1,2) \text { / Lenhosa }(2 \text {, } \\
\text { 3) }\end{array}$ & $\begin{array}{l}\text { Sementes, } \\
\text { brotações de } \\
\text { raízes (1) }\end{array}$ & $\begin{array}{l}\text { Suspeita de } \\
\text { ser tóxica } \\
\text { (4), Caule } \\
\text { cortante (1) }\end{array}$ & $\begin{array}{l}\text { 1- Obs. de campo } \\
\text { 2- Herbário IAN } \\
\text { 3- Corrêa (1931) } \\
\text { 4- Albuquerque } \\
\text { (1980) }\end{array}$ \\
\hline $\begin{array}{l}\text { FLACOURTIACEAE } \\
\text { Casearia arborea Urb. }\end{array}$ & Tapichauarana (2) & Perene $(1,2)$ & $\begin{array}{l}\text { Arbóreo }(1,2) \text { / Lenhoso } \\
(1,2)\end{array}$ & $\begin{array}{l}\text { Sementes }(1 \\
\text { 2) }\end{array}$ & - & $\begin{array}{l}\text { 1- Obs. de campo } \\
\text { 2- Herbário IAN }\end{array}$ \\
\hline Banara guianensis Aubl. & $\begin{array}{l}\text { Lacre-branco (2), } \\
\text { andorinha (3) }\end{array}$ & Perene (1) & $\begin{array}{l}\text { Arbustivo (2) / Lenhoso } \\
(\mathbf{1 , 2})\end{array}$ & $\begin{array}{l}\text { Sementes }(1, \\
\text { 2) }\end{array}$ & - & $\begin{array}{l}\text { 1- Obs. de campo } \\
\text { 2- Corrêa (1969) } \\
\text { 3- Camarão et al. } \\
\quad(1990) \\
\end{array}$ \\
\hline $\begin{array}{l}\text { GENTIANACEAE } \\
\text { Coutoubea spicata } \text { H. B. \& K. }\end{array}$ & $\begin{array}{l}\text { Tingeu, alfavaca- } \\
\text { brava (2), cutubea } \\
\text { (3) }\end{array}$ & Anual $(2,3)$ & $\begin{array}{l}\text { Ereto }(1,3) \text { / Herbáceo } \\
(\mathbf{1}, \mathbf{2})\end{array}$ & $\begin{array}{l}\text { Sementes }(1, \\
2,3)\end{array}$ & - & $\begin{array}{l}\text { 1- Obs. de campo } \\
\text { 2- Herbário IAN } \\
\text { 3- Corrêa (1931) }\end{array}$ \\
\hline $\begin{array}{l}\text { POACEAE } \\
\text { Homolepis aturensis Chase }\end{array}$ & $\begin{array}{l}\text { Capim-pacuã, } \\
\text { capim-amargoso } \\
\text { (3) }\end{array}$ & Perene (2) & $\begin{array}{l}\text { Decumbente (1)/ } \\
\text { Herbáceo }(\mathbf{1 , 2})\end{array}$ & $\begin{array}{l}\text { Sementes (1, } \\
2) \text {, } \\
\text { vegetativament } \\
\text { e (2) }\end{array}$ & $\begin{array}{l}\text { Suspeita de } \\
\text { ser tóxica (4) }\end{array}$ & $\begin{array}{l}\text { 1-Obs. de campo } \\
\text { 2-Morales et al. } \\
\quad \text { (1974) } \\
\text { 3-Diaz et al. (1978) } \\
\text { 4- Albuquerque } \\
\quad(1980)\end{array}$ \\
\hline Imperata brasiliensis Trin. & $\begin{array}{l}\text { Capim-sapé, } \\
\text { massapé, capim- } \\
\text { agreste, jucapé ( } 3 \text {, } \\
\text { 5), sucapé, capim- } \\
\text { estrepe (5) }\end{array}$ & Perene $(4,5)$ & $\begin{array}{l}\text { Cespitoso }(1,2) / \\
\text { Herbáceo }(\mathbf{1 , 2 , 4 , 5 )}\end{array}$ & $\begin{array}{l}\text { Sementes, } \\
\text { rizomas }(1,3, \\
4,5)\end{array}$ & - & $\begin{array}{l}\text { 1- Obs. de campo } \\
\text { 2- Herbário IAN } \\
\text { 3- Corrêa (1926) } \\
\text { 4- Lorenzi (1976) } \\
\text { 5- Kissmann (1997) }\end{array}$ \\
\hline
\end{tabular}

Continua... 
Tabela 2, Continuação

\begin{tabular}{|c|c|c|c|c|c|c|}
\hline $\begin{array}{l}\text { FAMÍLIA / NOME } \\
\text { CIENTÍFICO }\end{array}$ & $\begin{array}{c}\text { NOME } \\
\text { VULGAR }\end{array}$ & $\begin{array}{l}\text { CICLO DE } \\
\text { VIDA }\end{array}$ & $\begin{array}{c}\text { HÁBITO DE } \\
\text { CRESCIMENTO / } \\
\text { CONSISTÊNCIA DO } \\
\text { CAULE }\end{array}$ & REPRODUÇÃO & $\begin{array}{l}\text { TÓXICAS / } \\
\text { INJÚRIAS }\end{array}$ & REFERÊNCIAS \\
\hline Panicum pilosum $\mathrm{SW}$. & - & Perene (2) & $\begin{array}{l}\text { Cespitoso decumbente (2) } \\
\text { / Herbáceo }(\mathbf{1}, \mathbf{2})\end{array}$ & Sementes (1) & $\begin{array}{l}\text { Suspeita de } \\
\text { ser tóxica (3) }\end{array}$ & $\begin{array}{l}\text { 1-Obs. de campo } \\
\text { 2- Herbário IAN } \\
\text { 3- Albuquerque } \\
\text { (1980) }\end{array}$ \\
\hline Paspalum conjugatum Berg. & $\begin{array}{l}\text { Capim-pacuã (2), } \\
\text { capim-azedo, } \\
\text { grama-azeda, } \\
\text { capim-gordo, } \\
\text { capim-forquilha, } \\
\text { capim-marreca (3) }\end{array}$ & Perene $(2,3)$ & $\begin{array}{l}\text { Prostrado }(1,2) / \\
\text { Herbáceo }(\mathbf{1}, \mathbf{3})\end{array}$ & $\begin{array}{l}\text { Sementes, } \\
\text { estolhos }(1,3)\end{array}$ & - & $\begin{array}{l}\text { 1- Obs. de campo } \\
\text { 2- Herbário IAN } \\
\text { 3- Kissmann (1997) }\end{array}$ \\
\hline Paspalum maritimum Trin. & $\begin{array}{l}\text { Capim-gengibre ( } 1 \text {, } \\
2,3,4,5) \text {, capim- } \\
\text { pernambuco, } \\
\text { capim-jacaré }(4), \\
\text { capim-jaguqré (5) }\end{array}$ & $\begin{array}{l}\text { Perene }(1,2, \\
4,5)\end{array}$ & $\begin{array}{l}\text { Prostrado (1) / Herbáceo } \\
(\mathbf{1 , 5 )}\end{array}$ & $\begin{array}{l}\text { Sementes, } \\
\text { estolões, } \\
\text { rizomas }(1,3 \text {, } \\
4,5)\end{array}$ & - & $\begin{array}{l}\text { 1- Obs. de campo } \\
\text { 2- Herbário IAN } \\
\text { 3- Corrêa (1926) } \\
\text { 4- Lorenzi (1994) } \\
\text { 5- Kissmann (1997) }\end{array}$ \\
\hline $\begin{array}{l}\text { GUTTIFERAE } \\
\text { Vismia guianensis (Aublet) } \\
\text { Choisy }\end{array}$ & Lacre (1) & Perene (1) & $\begin{array}{l}\text { Arbóreo (1) / Lenhoso (1, } \\
\text { 2) }\end{array}$ & $\begin{array}{l}\text { Sementes (1, } \\
\text { 2), brotações } \\
\text { de raízes (3) }\end{array}$ & - & $\begin{array}{l}\text { 1- Obs. de campo } \\
\text { 2- Herbário IAN } \\
\text { 3- Dias Filho (1990) }\end{array}$ \\
\hline $\begin{array}{l}\text { LABIATAE } \\
\text { Hyptis atrorubens Poit. }\end{array}$ & Hortelazinho (1) & - & $\begin{array}{l}\text { Prostrado (1) / Herbáceo } \\
\text { (1) }\end{array}$ & Sementes (1) & - & 1- Obs. de campo \\
\hline $\begin{array}{l}\text { LECYTHIDACEAE } \\
\text { Lecythis lurida (Miers) S. A. } \\
\text { Mori. }\end{array}$ & Jarana, inhaúba (2) & Perene (2) & Arbóreo (2)/Lenhoso (1) & Sementes (1) & - & $\begin{array}{l}\text { 1- Obs. de campo } \\
\text { 2- Herbário IAN }\end{array}$ \\
\hline $\begin{array}{l}\text { FABACEAE } \\
\text { Desmodium axillare DC. }\end{array}$ & Amendoeira (3) & - & $\begin{array}{l}\text { Prostrado }(1,2,3) / \\
\text { Herbáceo (1) }\end{array}$ & \begin{tabular}{|l|} 
Sementes (1, \\
2), estolhos (3)
\end{tabular} & - & $\begin{array}{l}\text { 1- Obs. de campo } \\
\text { 2- Herbário IAN } \\
\text { 3- Corrêa (1926) }\end{array}$ \\
\hline $\begin{array}{l}\text { Desmodium barbatum Benth. } \\
\& \text { Oerst. }\end{array}$ & $\begin{array}{l}\text { Carrapicho (2), } \\
\text { carrapicho-beiço- } \\
\text { de-boi, pega-pega, } \\
\text { barbadinho (4), } \\
\text { amor-do-campo (3) }\end{array}$ & $\begin{array}{l}\text { Anual }(2), \\
\text { perene }(3,4)\end{array}$ & $\begin{array}{l}\text { Rizomatosa, prostrada (3, } \\
\text { 4) / Lenhosa }(\mathbf{1}, \mathbf{3})\end{array}$ & $\begin{array}{l}\text { Sementes, } \\
\text { rizomas, (1, 3, } \\
\text { 4) }\end{array}$ & - & $\begin{array}{l}\text { 1- Obs. de campo } \\
\text { 2- Herbário IAN } \\
\text { 3- Corrêa (1926) } \\
\text { 4- Kissmam \& } \\
\text { Groth (1992) }\end{array}$ \\
\hline $\begin{array}{l}\text { Desmodium canum Schins \& } \\
\text { Thellung }\end{array}$ & Pega-pega (2) & - & Ereto $(1,2)$ / Lenhoso (1) & Sementes (1) & - & $\begin{array}{l}\text { 1- Obs. de campo } \\
\text { 2- Herbário IAN }\end{array}$ \\
\hline Schrankia leptocarpa DC. & $\begin{array}{l}\text { Juquiri (2), juquiri- } \\
\text { carrasco (3) }\end{array}$ & - & $\begin{array}{l}\text { Prostrada (1) ou trepadeira } \\
\text { (3)/ Lenhoso (1) }\end{array}$ & Sementes (1) & $\begin{array}{l}\text { Espinhos no } \\
\text { caule (1) }\end{array}$ & $\begin{array}{l}\text { 1-Obs. de campo } \\
\text { 2- Herbário IAN } \\
\text { 3- Corrêa (1969) }\end{array}$ \\
\hline $\begin{array}{l}\text { MALVACEAE } \\
\text { Sida rhombifolia linn. }\end{array}$ & $\begin{array}{l}\text { Maiva-preta }(2,3), \\
\text { vassoura-relógio, } \\
\text { vassourinha }(3), \\
\text { guanxuma, mata- } \\
\text { pasto, relógio }(4)\end{array}$ & $\begin{array}{l}\text { Anual }(3,4) \\
\text { ou perene }(4)\end{array}$ & $\begin{array}{l}\text { Subarbustivo }(1,2), \text { ereto } \\
\text { (4)/Lenhoso (1) }\end{array}$ & $\begin{array}{l}\text { Sementes }(1, \\
2,4)\end{array}$ & - & $\begin{array}{l}\text { 1- Obs. de campo } \\
\text { 2- Herbário IAN } \\
\text { 3- Corrêa (1974) } \\
\text { 4- Lorenzi (1994) }\end{array}$ \\
\hline Sida urens Linn. var. urens & $\begin{array}{l}\text { Malva (2), } \\
\text { guaxima, guaxuma } \\
\text { (3) }\end{array}$ & - & $\begin{array}{l}\text { Prostrado }(1,3) \text { ou ereto } \\
\text { (3) / Lenhoso }(\mathbf{1}, \mathbf{3})\end{array}$ & Sementes (1) & - & $\begin{array}{l}\text { 1- Obs. de campo } \\
\text { 2- Herbário IAN } \\
\text { 3- Corrêa (1952) }\end{array}$ \\
\hline $\begin{array}{l}\text { MELASTOMATACEAE } \\
\text { Pterolepis trichotoma } \text { Cogn. }\end{array}$ & - & Anual (2) & $\begin{array}{l}\text { Subarbustivo (1)/ } \\
\text { Lenhoso (1) }\end{array}$ & Sementes (1) & - & $\begin{array}{l}\text { 1- Obs. de campo } \\
\text { 2- Herbário IAN }\end{array}$ \\
\hline $\begin{array}{l}\text { RUBIACEAE } \\
\text { Borreria latifolia } \text { Schum. }\end{array}$ & $\begin{array}{l}\text { Vassourinha-de- } \\
\text { botão, poaia-do- } \\
\text { campo, cordão-de- } \\
\text { frade-branco (3), } \\
\text { erva-de-lagarto (4) }\end{array}$ & $\begin{array}{l}\text { Perene (3), } \\
\text { anual (4) }\end{array}$ & $\begin{array}{l}\text { Decumbente (2), prostrado } \\
(3,4) \text { ou ascendente }(4) / \\
\text { Sublenhoso }(1) \text { ou } \\
\text { herbáceo }(\mathbf{4})\end{array}$ & $\begin{array}{l}\text { Sementes }(1, \\
3,4)\end{array}$ & - & $\begin{array}{l}\text { 1- Obs. de campo } \\
\text { 2- Herbário IAN } \\
\text { 3- Corrêa (1974) } \\
\text { 4- Lorenzi (1994) }\end{array}$ \\
\hline $\begin{array}{l}\text { Borreria suaveolens G.F.W. } \\
\text { Mey. }\end{array}$ & $\begin{array}{l}\text { Vassourinha-de- } \\
\text { botão (1), poaia- } \\
\text { do-cerrado (2) }\end{array}$ & Anual (1) & $\begin{array}{l}\text { Decumbente (1) / } \\
\text { Herbáceo (1) }\end{array}$ & Sementes (1) & - & $\begin{array}{l}\text { 1- Obs. de campo } \\
\text { 2- Corrêa (1974) }\end{array}$ \\
\hline $\begin{array}{l}\text { Borreria verticillata (L.) G. } \\
\text { F.W. Mey. }\end{array}$ & $\begin{array}{l}\text { Vassourinha-de- } \\
\text { botão, cordão-de- } \\
\text { frade, erva-botão, } \\
\text { poaia-comprida, } \\
\text { perpétua-do-mato } \\
\text { (2) }\end{array}$ & $\begin{array}{l}\text { Anual ou } \\
\text { perene (2) }\end{array}$ & $\begin{array}{l}\text { Subarbustivo }(1,2) / \\
\text { Lenhoso }(\mathbf{1}, \mathbf{2})\end{array}$ & $\begin{array}{l}\text { Sementes }(1, \\
2)\end{array}$ & - & $\begin{array}{l}\text { 1- Obs. de campo } \\
\text { 2- Corrêa (1975) }\end{array}$ \\
\hline
\end{tabular}

Continua... 
Tabela 2, Continuação

\begin{tabular}{|c|c|c|c|c|c|c|}
\hline $\begin{array}{l}\text { FAMÍLIA / NOME } \\
\text { CIENTÍFICO }\end{array}$ & $\begin{array}{l}\text { NOME } \\
\text { VULGAR }\end{array}$ & $\begin{array}{l}\text { CICLO DE } \\
\text { VIDA }\end{array}$ & $\begin{array}{c}\text { HÁBITO DE } \\
\text { CRESCIMENTO / } \\
\text { CONSISTÊNCIA DO } \\
\text { CAULE } \\
\end{array}$ & REPRODUÇÃO & $\begin{array}{l}\text { TÓXICAS / } \\
\text { INJÚRIAS }\end{array}$ & REFERÊNCIAS \\
\hline Hemidiodia ocimifolia Schum. & $\begin{array}{l}\text { Vassourinha-de- } \\
\text { botão (1) }\end{array}$ & - & $\begin{array}{l}\text { Subarbustivo (1) / } \\
\text { Lenhoso (1) }\end{array}$ & Sementes (1) & - & 1- Obs. de campo \\
\hline Sabicea villosa Roen. \& Schut. & Santo-antônio (1) & - & $\begin{array}{l}\text { Prostrado (1) / Herbáceo } \\
\text { (1) }\end{array}$ & $\begin{array}{l}\text { Sementes, } \\
\text { estacas (1) }\end{array}$ & - & 1- Obs. de campo \\
\hline $\begin{array}{l}\text { SOLANACEAE } \\
\text { Solanum caavurana Lam. }\end{array}$ & Caavurana (2) & - & $\begin{array}{l}\text { Subarbustivo }(1,2) / \\
\text { Lenhoso (1) }\end{array}$ & $\begin{array}{l}\text { Sementes }(1, \\
2)\end{array}$ & - & $\begin{array}{l}\text { 1- Obs. de campo } \\
\text { 2- Corrêa (1926) }\end{array}$ \\
\hline Solanum crinitum Lam. & $\begin{array}{l}\text { Jurubeba (1), fruta- } \\
\text { de-lobo, lobeira (2) }\end{array}$ & - & $\begin{array}{l}\text { Subarbustivo (1), } \\
\text { arbustivo (2)/ } \\
\text { Lenhoso (1) } \\
\end{array}$ & $\begin{array}{l}\text { Sementes (1), } \\
\text { brotaçôes de } \\
\text { raízes (3) }\end{array}$ & $\begin{array}{l}\text { Possui } \\
\text { espinhos (3) }\end{array}$ & $\begin{array}{l}\text { 1- Obs. de campo } \\
\text { 2- Corrêa (1952) } \\
\text { 3- Dias Filho (1990) }\end{array}$ \\
\hline Solamum stramonifolium Jacq. & $\begin{array}{l}\text { Juá, jurubeba, } \\
\text { juúna (2) }\end{array}$ & - & $\begin{array}{l}\text { Subarbustivo (1) / } \\
\text { Lenhoso (1) }\end{array}$ & Sementes (1) & $\begin{array}{l}\text { Possui } \\
\text { espinhos (1) }\end{array}$ & $\begin{array}{l}\text { 1- Obs. de campo } \\
\text { 2- Herbário IAN }\end{array}$ \\
\hline $\begin{array}{l}\text { VERBENACEAE } \\
\text { Stachytarpheta cayennensis } \\
\text { Schau. }\end{array}$ & $\begin{array}{l}\text { Rinchão (2), } \\
\text { gervão, aguará- } \\
\text { ponda, verbena- } \\
\text { falsa (3) }\end{array}$ & Perene (4) & $\begin{array}{l}\text { Subarbustivo }(1,2,3) / \\
\text { Lenhoso }(\mathbf{1}, \mathbf{2})\end{array}$ & $\begin{array}{l}\text { Sementes }(1, \\
2)\end{array}$ & - & $\begin{array}{l}\text { 1- Obs. de campo } \\
\text { 2- Herbário IAN } \\
\text { 3- Corrêa (1952) } \\
\text { 4- Dias Filho (1990) }\end{array}$ \\
\hline
\end{tabular}

OBS.: Os números entre parênteses, na mesma linha, correspondem às referências bibliográficas citadas na última coluna.

\section{AGRADECIMENTOS}

Os autores agradecem ao Eng.-Agrônomo Adriano Marta Júnior, dono da Fazenda Belém, pela cessão da área e do maquinário, pelo apoio prestado para a conclusão deste trabalho.

\section{LITERATURA CITADA}

ALBUQUERQUE, J.M. Plantas tóxicas: no jardim e no campo. Belém: FCAP, Serviço de Documentação e Informação, 1980. 120p.

AZEVEDO, G.P.C.; CARVALHO, R.A.; TEIXEIRA, R.NG.; SARMENTO, C.M.B.; RODRIGUES FILHO, J.A.; GONÇALVES, C.A.; OLIVEIRA, R.P. Características dos sistemas de produção de gado de corte na região bragantina. Belém: EMBRAPA - CPATU, 1994. 23p. (EMBRAPA CPATU. Documentos, 79).

BLANCO, H.G. Plantas daninhas e matocompetição. Piracicaba: ESALQ, 1976. 35p. (não publicado)

BLANCO, H.G. A importância dos estudos ecológicos nos programas de controle das plantas daninhas. O Biológico, n.38, p.343-350, 1972.

BOLETIM AGROMETEOROLÓGICO. Belém: EMBRAPA - CPATU, 1974 - 1987.
CAMARÃO, A.P.; SIMÃO NETO, M.; SERRÃO, E.A.S.; RODRIGUES, I.A.; LASCANO, C. Identificação e composição química de espécies de invasoras consumidas por bovinos em pastagens cultivadas em Paragominas, Pará. Belém: EMBRAPA-CPATU, 1990. 62p. (EMBRAPA-CPATU. Boletim de Pesquisa, 104).

CÁRDENAS, J.; REYES, C.E.; DOLL, J. Tropical weeds. Bogotá: ITALGRAF, 1972. v.1. 341p.

CENSO AGROPECUÁRIO. Rio de Janeiro: FIBGE, 1985.

CENSO AGROPECUÁRIO. Rio de Janeiro: FIBGE, 1995-1996.

CORREAA, M.P. Dicionário das plantas úteis do Brasil e exóticas cultivadas. Rio de Janeiro: Ministério da Agricultura, 1926. v.1. 747p.

CORRÊA, M.P. Dicionário das plantas úteis do Brasil e exóticas cultivadas. Rio de Janeiro: Ministério da Agricultura, 1931. v.2. 707p.

CORREAA, M.P. Dicionário das plantas úteis do Brasil e exóticas cultivadas. Rio de Janeiro: Ministério da Agricultura, 1952. v.3. 646p.

CORREAA, M.P. Dicionário das plantas úteis do Brasil e exóticas cultivadas. Rio de Janeiro: Ministério da Agricultura, 1969. v.4. 765p.

Planta Daninha, Viçosa-MG, v.19, n.1, p.11-21, 2001 
CORRÊA, M.P. Dicionário das plantas úteis do Brasil e exóticas cultivadas. Rio de Janeiro: Ministério da Agricultura, 1974. v.5. 687p.

CORRÊA, M.P. Dicionário das plantas úteis do Brasil e exóticas cultivadas. Rio de Janeiro: Ministério da Agricultura, 1975. v.6. 777p.

DANTAS, M.; RODRIGUES, I.A. Plantas invasoras de pastagens cultivadas na Amazônia. Belém: EMBRAPA-CPATU, 1980. 23p.(EMBRAPACPATU. Boletim de pesquisa, 1).

DEUBER, R. Ciência das plantas daninhas: fundamentos. Jaboticabal: FUNEP, 1992. v.1. $431 \mathrm{p}$.

DIAS FILHO, M.B. Plantas invasoras em pastagens cultivadas da Amazônia: estratégias de manejo e controle. Belém: EMBRAPA-CPATU, 1990. 103p. (EMBRAPA-CPATU. Documentos, 52).

DIAS FILHO, M.B. Pastagens cultivadas na Amazônia Oriental brasileira: processos e causas de degradação e estratégias de recuperação. In: DIAS, L.E., MELLO, J.W.V. (Eds.) Recuperação de áreas degradadas. Viçosa: UFV, 1998. p.135-147.

DIAZ, A.M.P., PORTUS, M.I.G., SIlvA, M.F. Algumas plantas cianogenéticas da região amazônica. Acta Amazônica, v.8, n.4, p.679$685,1978$.

GONÇALVES, C.A., PIMENTEL, D.M., SANTOS FILHO, B.G. Plantas invasoras de pastagens do Estado do Pará. Belém: IPEAN, 1974.

HECHT, S. Leguminosas espontaneas en praduras amazonicas cultivadas y su potencial forrajero. In: TERGAS, L.E., SANCHES, P.A. (Eds.) Produción de pastos en suelos de los Trópicos. Cali: CIAT, 1979. p.71-84.

HOMMA, A.K.O.; MARQUES, J.R.F.; GUIMARÃES NETO, J.T.; LIMA, P.R.G. Algumas características da pecuária de corte na região leste do Estado do Pará. Belém: 1977. 8p. (não publicado)

INDEX KEWENSIS. Oxford: Oxford University Press, 1993. (CD - Rom)

KISSMAN, K.G.; GROTH, D. Plantas infestantes e nocivas. São Paulo: BASF Brasileira, 1992. 798 .

Planta Daninha, Viçosa-MG, v.19, n.1, p.11-21, 2001
KISSMAN, K.G. Plantas infestantes e nocivas. São Paulo: BASF Brasileira, 1997. 825p.

LORENZI, H.J. (Coord). Manual de identificação e controle de plantas daninhas: plantio direto e convencional. 4.ed. Nova Odessa: Plantarum, 1994. 336p.

LORENZI, H.J. Principais ervas daninhas do estado do Paraná. Londrina: IAPAR, 1976. 208p. ilust. (IAPAR. Boletim Técnico, 2).

MASCARENHAS, R.E.B.; MODESTO JÚNIOR, M.S.; MÜLLER, N.R.M. Levantamento florístico da regeneração natural em uma área de várzea do rio Guamá - Estuário Amazônico. Belém: EMBRAPA - CPATU, 1996. (EMBRAPA-CPATU. Boletim de Pesquisa, 163).

MASCARENHAS, R.E.B.; MODESTO JÚNIOR, M.S.; MÜLLER, N.R.M. Levantamento florístico em área de cultivo de arroz irrigado em várzea do rio Guamá - Estado do Pará. Belém: EMBRAPA - CPATU, 1997. (EMBRAPA-CPATU. Boletim de Pesquisa, 173).

MASCARENHAS, R.E.B.; MODESTO JÚNIOR, M.S.; SILVEIRA FILHO, A.; SOUZA FILHO, A.P.S.; DUTRA, S.; TEIXEIRA NETO, J.F. Controle de plantas daninhas em pastagens cultivadas da Amazônia Oriental. Belém: EMBRAPA Amazônia Oriental, 1999. 29p (EMBRAPA Amazônia Oriental, Documentos, 6)

MORALES, L.; SOLANO, F.; DOLL, J.; OTAVO, J.; VARGAS, D. Algumas malezas de potrelos tropicales. Colômbia: Instituto Colombiano Agropecuário, 1974. 273p. (ICA. Manual de Assistência Técnica, 19).

PIRES, J.M.; KOURY, H.M. Estudo de um trecho de mata de várzea próximo de Belém. Belém: IAN, 1959. p.3-44. (IAN. Boletim Técnico, 36).

SERRÃO, E.A.S.; FALESI, I.C. Pastagens do trópico úmido brasileiro. In: SIMPÓSIO SOBRE MANEJO DE PASTAGENS, 41, 1977, Piracicaba. Anais...Piracicaba: ESALQ, 1977. p.177-242.

SOUZA, S.G.A.; WANDELli, E.V.; PERIN, R. Dinâmica de populações de Borreria verticillata em quatro sistemas agroflorestais na Amazônia Ocidental. In: CONGRESSO BRASILEIRO DA CIÊNCIA DAS PLANTAS DANINHAS, 21., 1997, Caxambu. Resumos... Viçosa: SBCPD, 1997. p.22. 
TEIXEIRA, L.B.; CANTO, A.C.; HOMMA, A.K.O. Controle de ervas invasoras em pastagens na Amazônia Ocidental. Manaus: IPAAOc, 1973. 18p. (IPAAOc. Circular, 3).

VEIGA, J.B.; SERRÃO, E.A.S. Recuperação de pasturas en la region este de la Amazônia brasileña. Pasturas Trop., v.9, n.3, p.40-43, 1987.
VIDAL, W.N.; VIDAL, M.R.R. Botânica-Organografia: quadros sinópticos, listrados de fanerógamos. Viçosa: UFV, 1986. 114p.

VINHA, S.G.; CADIMA, A.; SANTOS, O.M. A fase pioneira de uma sucessão secundária no sul da Bahia: estrutura e composição química da vegetação. R. Theobroma, v.13, n.1, p.27-34, 1983. 